\title{
PENGEMBANGAN APLIKASI DOCUMENT FLOW BERBASIS WEB MODUL ADMINISTRATOR DAN PEGAWAI PADA BANK INDONESIA
}

\author{
Rini Malfiany ${ }^{1}$, Ahmad Fauzi ${ }^{2}$ \\ ${ }^{1}$ STMIK ROSMA Karawang, Manajemen Informatika, ${ }^{2}$ UBP Karawang, Teknik Informatika \\ e-mail : ${ }^{1}$ rini.malfiany@gmail.com, ${ }^{2}$ ahmad.fauzi@ubpkarawang.ac.id
}

\begin{abstract}
Abstrak
Bank Indonesia sebagai BUMN mempunyai tujuan tunggal mencapai dan memelihara kestabilan nilai rupiah. Kestabilan nilai rupiah ini mengandung dua aspek, yaitu kestabilan nilai mata uang terhadap barang dan jasa, serta kestabilan terhadap mata uang negara lain. Departemen Pengelolaan Sistem Informasi (DPSI) merupakan salah satu organisasi pada Bank Indonesia yang memiliki beberapa divisi. Salah satunya Pengembangan dan Pemeliharaan Aplikasi - Sistem Pembayaran (PPA-SP). Divisi PPASP ini mempunyai dokumen yang belum dikelola secara maksimal. Pengelolaan dokumen tersebut memiliki alur dan tata cara untuk mengelolanya. Banyak dokumen yang masih disimpan bukan pada tempatnya. Disposisi dokumen dilakukan agendaris dengan membawa dokumen yang akan didisposisikan kepada staff lain untuk mendapatkan disposisi dokumen tersebut. Sebuah sistem dibutuhkan untuk membantu tugas agendaris dan pegawai pada Divisi PPA-SP dalam pendisposisian dokumen dan pengarsipan dokumen. Aplikasi ini dinamakan Document Flow, dibuat untuk membantu tugas agendaris dan pegawai pada Divisi PPA-SP dalam mengelola dokumen. Aplikasi Document Flow ini dibuat dengan metode pengembangan perangkat lunak evolutionary prototype. Hasil akhir dari sistem adalah laporan informasi dokumen, dan informasi disposisi. Aplikasi Document Flow pada Divisi PPA-SP ini dibuat untuk mencapai efisiensi waktu agar bisa lebih cepat dalam proses pengolahan dokumen, sehingga bisa memberikan kemudahan kepada agendaris dan pegawai pada Divisi PPA-SP.
\end{abstract}

Kata Kunci : Aplikasi Document Flow, metode evolutionary prototipe, Sistem Pembayaran Bank Indonesia

\section{PENDAHULUAN}

Sejarah kelembagaan Bank Indonesia dimulai sejak berlakunya Undang-Undang (UU) No. 11/1953 tentang Penetapan Undang-Undang Pokok Bank Indonesia pada tanggal 1 Juli 1953. Dalam melakukan tugasnya sebagai bank sentral, Bank Indonesia dipimpin oleh Dewan Moneter, Direksi, dan Dewan Penasehat. Di tangan Dewan Moneter inilah, kebijakan moneter ditetapkan, meski tanggung jawabnya berada pada pemerintah. Setelah sempat dilebur ke dalam bank tunggal, pada masa awal orde baru, landasan Bank Indonesia berubah melalui UU No. 13/1968 tentang Bank Sentral. Sejak saat itu, Bank Indonesia berfungsi sebagai bank sentral dan sekaligus membantu pemerintah dalam pembangunan dengan menjalankan kebijakan yang ditetapkan pemerintah dengan bantuan Dewan Moneter. Dengan demikian, Bank Indonesia tidak lagi dipimpin oleh Dewan Moneter. Setelah orde baru berlalu, Bank Indonesia dapat mencapai independensinya melalui UU No. 23/1999 tentang Bank Indonesia yang kemudian diubah dengan UU No. 3/2004. Sejak saat itu, Bank Indonesia memiliki kedudukan khusus dalam struktur kenegaraan sebagai lembaga negara yang independen dan bebas dari campur tangan pemerintah dan/atau pihak-pihak lain. Namun, dalam melaksanakan kebijakan moneter secara berkelanjutan, konsisten, dan transparan, Bank Indonesia harus mempertimbangkan pula kebijakan umum pemerintah di bidang perekonomian.

Sebagai sebuah lembaga Badan Usaha Milik Negara (BUMN) Bank Indonesia bertugas untuk mengatur nilai tukar rupiah. Bank Indonesia berkewajiban untuk memberikan pelayanan yang baik dan profesional. Pelayanan akan baik apabila semua sistem berjalan dengan baik. Departemen Pengembangan Sistem Informasi (DPSI) merupakan departemen yang mengatur jalannya sistem informasi dan aplikasi yang dijalankan pada Bank Indonesia. DPSI dibagi menjadi dua divisi, yaitu divisi Pengembangan dan Pemeliharaan Aplikasi Bidang Manajemen Intern (PPA-MI) dan divisi Pengembangan dan Pemeliharaan Aplikasi Bidang Sistem Pembayaran (PPA-SP). Divisi PPA-SP menangani jalannya aplikasi dibidang pembayaran seperti transaksi-transaksi yang dilakukan oleh Bank Indonesia. 
Divisi PPA-SP ini mempunyai dokumen yang belum dikelola secara maksimal. Pengelolaan dokumen tersebut memiliki alur dan tata cara untuk mengelolanya. Banyak dokumen yang masih disimpan bukan pada tempatnya. Saat dokumen tersebut harus didisposisi, agendaris dan pegawai masih menggunakan cara manual untuk mendapatkan disposisi dokumen tersebut. Sebuah sistem dibutuhkan untuk membantu tugas agendaris dan pegawai pada Divisi PPA-SP. Aplikasi ini dinamakan Document Flow, dibuat untuk membantu tugas agendaris dan pegawai pada Divisi PPA-SP dalam mengelola dokumen. Aplikasi Document Flow ini dibuat berbasis web agar satu divisi bisa menggunakan aplikasi ini dikomputer masing-masing.

Tujuan mengembangkan aplikasi document flow adalah untuk pengelolaan dan pencarian data yang berhubungan dengan data dokumen, data disposisi, data pegawai pada Divisi PPA-SP, dan mencetak laporan informasi dokumen, informasi disposisi, informasi pegawai dan informasi pencarian dokumen berbentuk PDF dan Excel.

\section{TINJAUAN PUSTAKA}

Unified Modelling Language (UML) adalah himpunan struktur dan teknik untuk pemodelan desain. UML terdiri atas diagram-diagram diantaranya adalah use case, Activity dan Class Diagram. Use case diagram adalah diagram untuk menunjukkan berbagai peran pengguna dan bagaimana peran-peran menggunakan sistem (Satzinger et al. 2010). Activity diagram adalah diagram yang mendeskripsikan alur aktifitas sesuai urutan dari proses bisnis yang akan di implementasikan pada aplikasi (Satzinger et al. 2010). Class Diagram adalah model grafis yang digunakan dalam pendekatan berorientasi objek untuk menunjukkan kelas objek dalam sistem. Class Diagram telah menjadi standar untuk model yang digunakan sistem berorientasi objek (Satzinger et al. 2010).

Entity Relationship Diagram (ERD) merupakan suatu model untuk menjelaskan hubungan antardata dalam basis data berdasarkan objek-objek dasar yang mempunyai hubungan Antara relasi (Yasin 2012). Basis data (database) adalah koleksi terpadu dari penyimpanan data yang dikelola terpusat dan dikendalikan. Sebuah database biasanya menyimpan informasi tentang puluhan atau ratusan jenis entitas atau kelas. Informasi yang disimpan meliputi atribut entitas atau kelas (misalnya, nama, harga, dan saldo rekening) serta hubungan antara entitas atau kelas (misalnya, pesanan milik pelanggan). Sebuah database juga menyimpan informasi deskriptif tentang data, seperti nama field, pembatasan nilai-nilai diperbolehkan, dan kontrol akses data sensitif. Database menyediakan tempat penyimpanan umum untuk data sehingga dapat digunakan bersama oleh seluruh organisasi (Satzinger et al. 2010). Menurut Michele Cyran (2005) Database Oracle adalah kumpulan data diperlakukan sebagai satu unit. Tujuan dari database adalah untuk menyimpan dan mengambil informasi terkait. Sebuah server database adalah kunci untuk memecahkan masalah-masalah manajemen informasi. Secara umum, server terpercaya mengelola sejumlah besar data dalam lingkungan multiuser sehingga banyak pengguna secara bersamaan dapat mengakses data yang sama. Semua ini dilakukan dengan tetap memberikan kinerja tinggi. Sebuah server database juga mencegah akses yang tidak sah dan menyediakan solusi yang efisien untuk pemulihan kegagalan.

Java Server Pages (JSP) merupakan teknologi yang didasarkan pada bahasa java, yang dapat digunakan untuk membentuk halaman-halaman Web yang bersifat dinamis. Teknologi ini dikembangkan oleh Sun Microsystems. Berbeda dengan Applet, suatu fitur pada bahasa java yang memungkinkan pengembang membuat aplikasi Web yang dieksekusi pada sisi klien. JSP menggunakan pendekatan pemrosesan disisi server (Kadir 2004).

Menurut Pressman (2010) pengujian black box atau juga disebut pengujian perilaku, berfokus pada persyaratan fungsional perangkat lunak. Artinya teknik pengujian black box memungkinkan untuk membuat beberapa kumpulan kondisi input yang sepenuhnya akan melakukan semua kebutuhan fungsional untuk program. Adapun tujuan dilakukannya pengujian tersebut adalah untuk menemukan kesalahan dalam kategori sebagai berikut: (1) fungsi yang salah atau hilang, (2) kesalahan interface, (3) kesalahan dalam struktur data atau akses basis data eksternal, (4) kesalahan perilaku atau kinerja, dan (5) kesalahan inisialisasi dan penghentian.

\section{METODE PENELITIAN}

Metode penelitian yang digunakan harus ditulis sesuai dengan cara ilmiah, yaitu rasional, empiris dan sistematis. Seyogyanya disebutkan waktu dan tempat penelitian secara jelas, berikut data maupun alat dan bahan yang dipakai dalam penelitian.

Metode yang dipilih oleh pengembang pada aplikasi ini adalah metode prototipe. Metode ini dipilih karena pembuatan aplikasi menggunakan waktu yang relatif singkat. Menurut Mcleod \& Schell 
(2008) prototipe adalah metode pengembangan perangkat lunak yang pengerjaan prototipenya terusmenerus disempurnakan sampai memiliki seluruh fungsionalitas yang dibutuhkan pengguna. Adapun skema dan penjelasan langkah-langkah dari prototipe evolusioner ini adalah sebagai berikut :

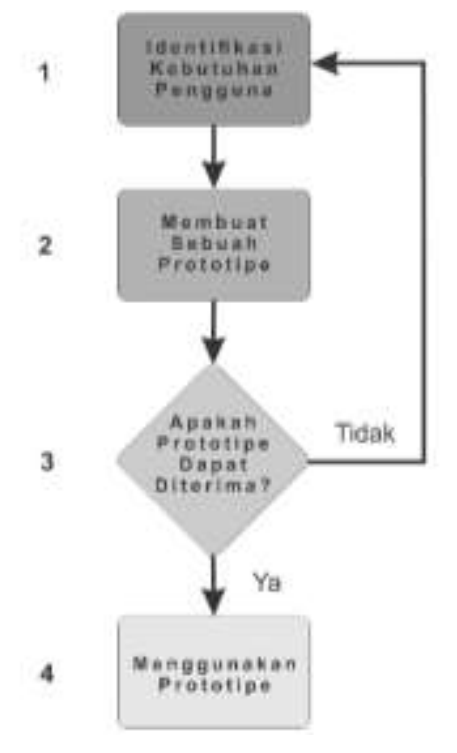

Gambar 1 : Skema Metode Penelitian

1 Identifikasi kebutuhan pengguna.

Identifikasi dilakukan dengan mewawancarai pengguna untuk mendapatkan ide mengenai apa yang dibutuhkan sistem. Tahap ini melakukan analisis terhadap kebutuhan pengguna, dan menghasilkan keluaran seperti analisis kebutuhan fungsional, analisis otoritas penggguna.

2 Membuat sebuah prototipe.

Pengembang mempergunakan satu alat prototyping atau lebih untuk membuat prototipe. Contoh dari alat-alat prototyping adalah generator aplikasi terintegrasi dan toolkit prototyping. Generator aplikasi terintegrasi (integrated application generator) adalah sistem piranti lunak siap pakai yang mampu membuat seluruh fitur yang diinginkan dari sistem baru berupa menu, laporan, tampilan, database, dan seterusnya. Toolkit prototyping meliputi sistem-sistem peranti lunak terpisah, seperti spreadsheet elektronik atau sistem manajemen basis data, yang masing-masing mampu membuat sebagian dari fitur-fitur sistem yang diinginkan. Tahap ini menghasilkan use case diagram, activity diagram, class diagram, dan entity-relationship diagram (ERD)

3 Menentukan apakah prototipe dapat diterima.

Tahap ini melakukan demo prototipe kepada para pengguna untuk mengetahui apakah telah memberikan hasil yang memuaskan. Jika ya, Langkah 4 akan diambil; jika tidak prototipe direvisi dengan mengulang kembali Langkah 1, 2, dan 3 dengan pemahaman yang lebih mengenai kebutuhan pengguna. Tahap ketiga ini pengembang juga melakukan pengujian dengan metode pengujian black box.

4 Menggunakan prototipe.

Pada tahap ini, pelanggan telah setuju dengan hasil prototipe yang telah dibuat oleh pengembang, dengan demikian, tahapan ini menandakan berakhirnya iterasi prototipe evolusioner dan sistem siap untuk digunakan.

\section{HASIL DAN PEMBAHASAN}

\subsection{Identifikasi Kebutuhan Pengguna}

Aplikasi Document Flow diartikan sebagai aplikasi yang berfungsi untuk membantu pengolahan dokumen/surat yang masuk. Keberadaan sistem ini pada Bank Indonesia di divisi PPA-SP adalah sebagai aplikasi tambahan untuk membantu dalam pengolahan dokumen/surat yang masuk pada divisi ini. Sistem ini diciptakan untuk mengolah data dokumen/surat yang masuk pada divisi PPA-SP, sehingga proses 
pengolahan data dokumen/surat dapat dilakukan dengan cepat serta menghindari kemungkinan terjadinya duplikasi data.

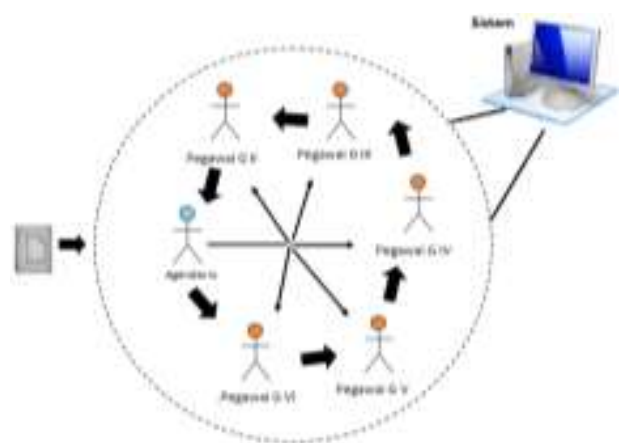

Gambar 2 Alur flow chart aplikasi document flow

a) Analisis Kebutuhan Informasi

Pada tahap analisis kebutuhan informasi dapat teridentifikasi bahwa kebutuhan informasi pada Aplikasi Document Flow yang akan dikembangkan adalah:

1) Pengelolaan data yang berhubungan dengan data dokumen, data disposisi, data pegawai pada Divisi PPA-SP.

2) Pencarian untuk tiap data.

3) Mencetak laporan informasi dokumen, informasi disposisi, informasi pegawai, dan informasi pencarian dokumen berbentuk $P D F$, Excel.

b) Analisis Kebutuhan Fungsional

Tahap analisis kebutuhan fungsional ini bertujuan untuk mendapatkan fungsi apa saja yang dibutuhkan dalam pengembangan sistem ini. Deskripsi mengenai kebutuhan fungsional prototipe pertama Aplikasi Document Flow sebagai berikut :

Tabel 1 Deskripsi kebutuhan fungsional prototipe

\begin{tabular}{ll}
\hline Fungsional & Memeriksa hak akses. \\
\hline Login user & Meskripsi \\
Manipulasi data Staff & Mencetak data Staff dalam bentuk PDF. \\
Cetak Laporan & Fungsional untuk mencari data Staff. \\
Pencarian data Staff & Fungsional untuk menambah data disposisi yang \\
Menambah disposisi & dilakukan oleh pegawai \\
& Mencetak data disposisi dalam bentuk PDF. \\
Cetak Laporan Disposisi & Fungsional untuk memberikan status pada dokumen \\
Menambah Status Dokumen & yang dilakukan oleh Pegawai \\
& Mencetak data dokumen dengan status dalam bentuk \\
Cetak Status Dokumen & PDF. \\
& Menampilkan data dokumen secara detail. \\
Detail data Dokumen & Mencetak data detail dokumen dalam bentuk PDF. \\
Cetak Detail Dokumen & Fungsional untuk mencari data dokumen. \\
Pencarian data Dokumen & Mencetak data dokumen dalam bentuk PDF. \\
Cetak data Dokumen & Fungsional untuk keluar dari system dan kembali ke \\
Logout user & halaman login. \\
&
\end{tabular}

c) Analisis Otoritas Pengguna

Proses identifikasi pengguna pada Aplikasi Document Flow Berbasis Web pada Bank Indonesia dilakukan dengan membagi karakteristik pengguna berdasarkan hak aksesnya. Hak akses pengguna aplikasi ini terbagi menjadi tiga user, yaitu administrator, pegawai, dan agendaris. Pada modul ini hak akses hanya dimiliki admin dan pegawai. Dimana admin disini hanya dapat mengatur pengguna yang akan menggunakan aplikasi ini seperti membuat akun untuk melakukan login pada aplikasi ini, dan pegawai yang menjalankan disposisi dokumen pada aplikasi ini. Deskripsi hak akses pengguna secara lengkap dapat dilihat pada tabel berikut : 
Tabel 2 Deskripsi hak akses

\begin{tabular}{ll}
\hline Kategori Pengguna & Kebutuhan Pengguna \\
\hline \multirow{3}{*}{ Administrator } & Login user \\
& Manipulasi data Staff \\
& Logout user \\
\hline \multirow{2}{*}{ Pegawai } & Login user \\
& Menambah Disposisi \\
& Menambah status dokumen \\
& Detail data dokumen \\
& Pencarian data dokumen \\
& Logout user \\
\hline
\end{tabular}

\subsection{Membuat Sebuah Prototipe}

Tahap ini menggambarkan tentang apa saja fungsi dari sistem yang dibutuhkan. Tahap perencanaan sistem merupakan proses menerjemahkan kebutuhan calon pengguna menjadi gambaran sistem yang mudah dipahami oleh pengguna. Perancangan ini terdiri atas Use Case Diagram, Activity Diagram, perancangan database, perancangan interface, perancangan navigasi, perancangan masukan, perancangan proses, dan perancangan keluaran.

a. Use case Diagram

Use case diagram mendeskripsikan interaksi antara sistem dengan aktor. Use case diagram membuat komunikasi antara pengembang dan pengguna menjadi mudah. Pada diagram ini terdapat 2 aktor yaitu administrator dan pegawai. Use-case diagram Aplikasi Document Flow adalah sebagai berikut :

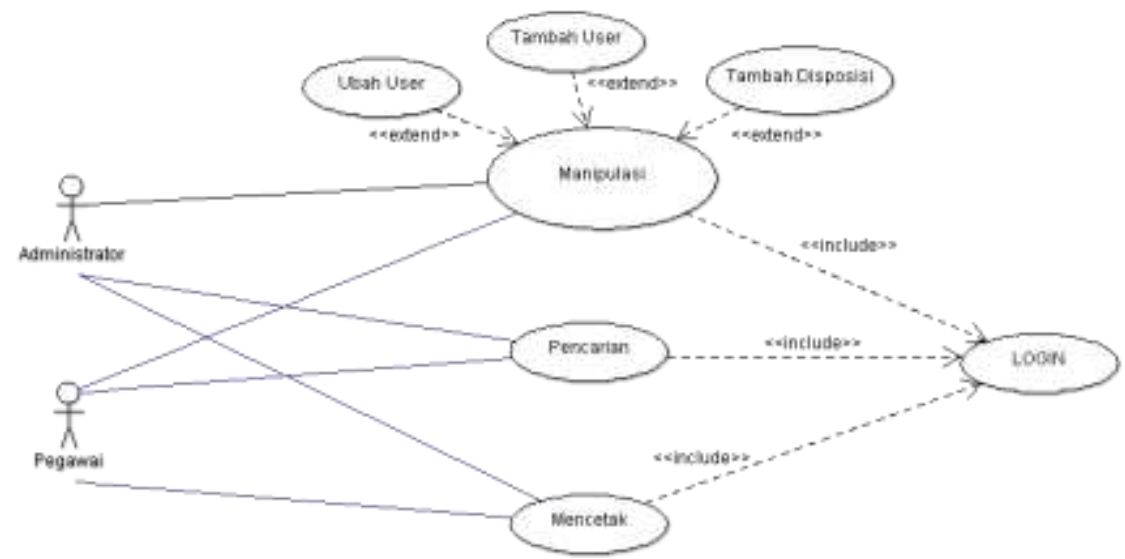

Gambar 3 Use case diagram Aplikasi

\section{b. Activity Diagram}

Activity diagram menggambarkan berbagai alur aktivitas dalam sistem yang sedang dirancang, bagaimana masing-masing alur berawal, decision yang mungkin terjadi, dan bagaimana mereka berakhir. Activity diagram juga dapat menggambarkan proses paralel yang mungkin terjadi pada beberapa eksekusi. Berikut Activity Diagram Login Admin : 


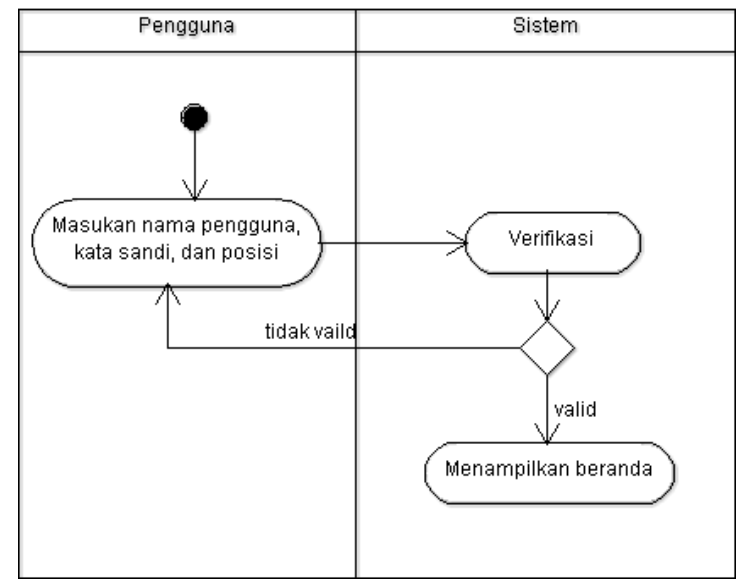

Gambar 3 Activity Diagram Login Admin

c. Perancangan Database

Tahap perancangan database dibagi menjadi perancangan database konseptual, perancangan database logis, dan perancangan database fisik.

1. Perancangan Database Konseptual, tujuan dari tahap ini adalah untuk menghasilkan sebuah skema konseptual dari database yang terbebas dari spesifikasi DBMS.

2. Perancangan Database Logis, selama fase ini, atau yang juga disebut desain database logis, skema konseptual dari pemodelan data tingkat tinggi diubah menjadi ke dalam bentuk pemodelan data dari DBMS yang dipilih. Tahap ini dapat dimulai setelah memilih jenis DBMS tertentu dan yang terakhir dapat disebut dengan system independent (data model-independent) logical design. Hasil dari tahap ini adalah sebuah skema konseptual yang telah diubah ke dalam bentuk pemodelan data dari database yang telah dipilih.

3. Perancangan Database Fisik, spesifikasi-spesifikasi dirancang untuk disimpan ke database dalam struktur fisik penyimpanan file, tempat penyimpanan, dan indeks-indeksnya.

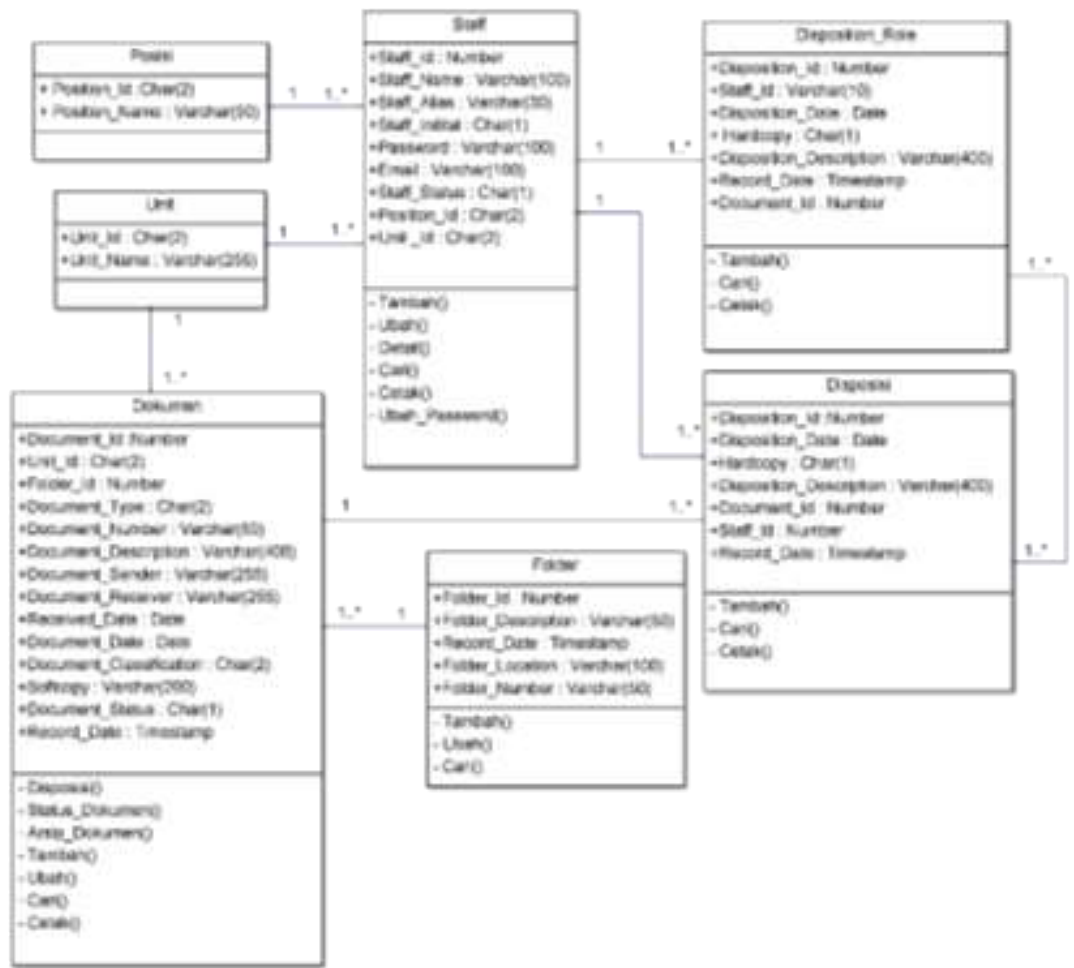

Gambar 4 Class Diagram Aplikasi

d. Perancangan Antarmuka

Perancangan bentuk dan tampilan antarmuka Aplikasi Document Flow ini berupa perpaduan antara teks dan gambar. Perancangan ini bertujuan untuk memberikan gambaran kepada pelanggan 
terhadap sistem yang akan dikembangkan. Dalam proses ini juga diharapkan pelanggan memberikan pendapat tentang tata letak program tersebut, sehingga pada proses implementasi nanti akan lebih mudah dan mengurangi perbaikan antarmuka program tersebut.

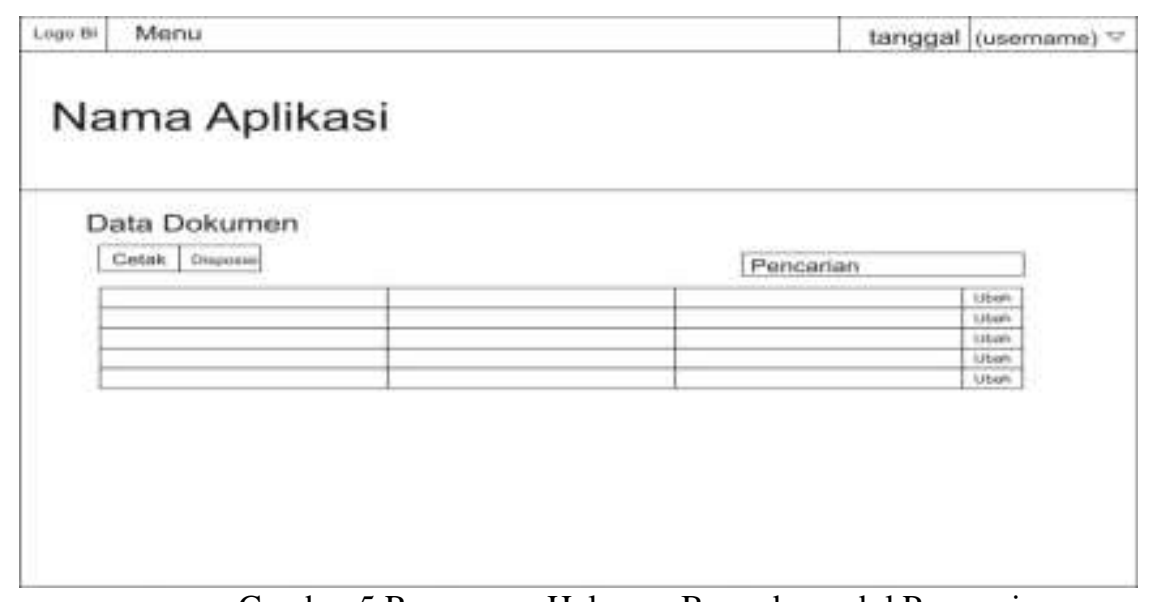

e. Perancangan Navigasi

Gambar 5 Rancangan Halaman Beranda modul Pegawai

Tahap perancangan navigasi bertujuan mengetahui dokumen yang berisi alur navigasi antar menu yang ada dalam sistem ini. Tujuan pembuatan menu navigasi adalah untuk memudahkan pengguna dalam membuka halaman perhalaman sistem. Struktur navigasi yang digunakan dalam sistem ini adalah struktur jejaring. Struktur jejaring digunakan karena halaman sistem dirancang dapat membuka hampir semua halaman dengan urutan tertentu dalam sistem ini.

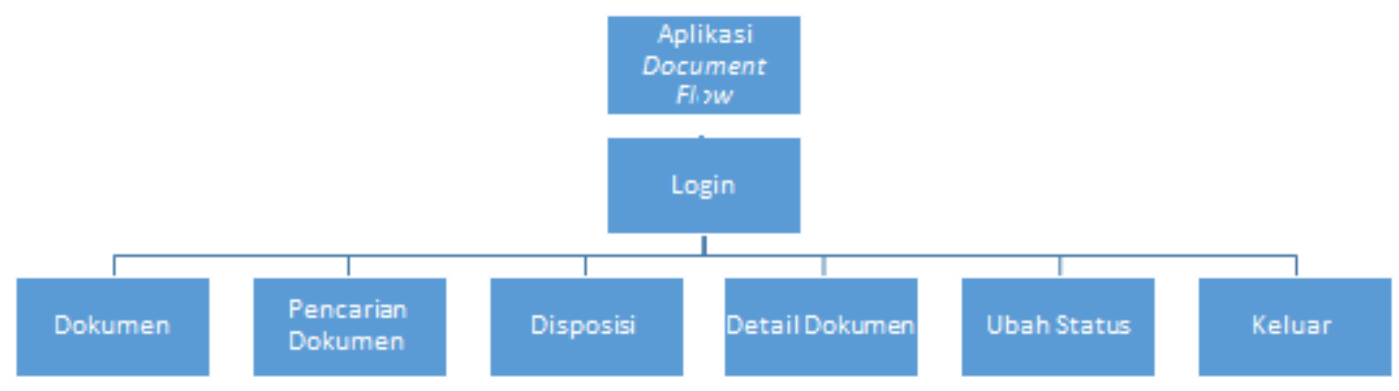

Gambar 6 Struktur navigasi modul pegawai

\subsection{Implementasi dan Pengujian Sistem}

Rancangan database yang telah dibuat sebelumnya kemudian diterapkan ke dalam sistem manajemen database. Aplikasi Document Flow menggunakan Oracle dalam pengelolaan database. Bahasa pemrograman JSP digunakan untuk mengolah masukan hingga menghasilkan keluaran yang diharapkan.

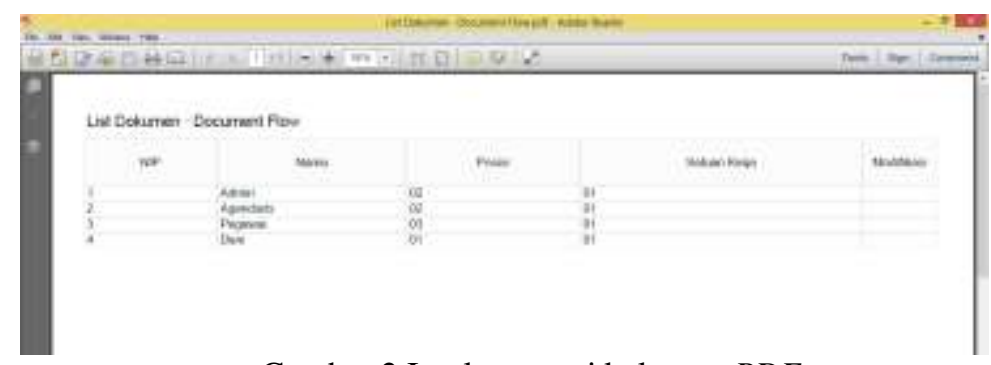

Gambar 2 Implementasi keluaran PDF

Pengujian dilakukan atas hasil implementasi aplikasi yang dikembangkan menggunakan pengujian black box.

Tabel 3 Pengujian manipulasi pengguna

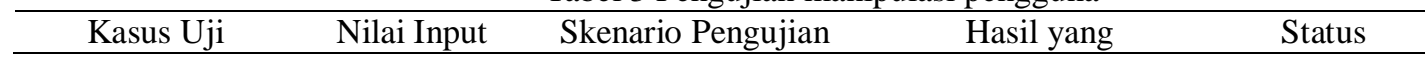




\begin{tabular}{|c|c|c|c|c|}
\hline & & & Diharapkan & \\
\hline \multirow[t]{3}{*}{$\begin{array}{l}\text { Pengujian } \\
\text { tambah } \\
\text { pengguna }\end{array}$} & Salah & dibiarkan & $\begin{array}{l}\text { Tampil pesan "kolom } \\
\text { masih ada yang } \\
\text { kosong", }\end{array}$ & Sukses \\
\hline & Salah & $\begin{array}{l}\text { Mengisi NIP dengan } \\
\text { data yang sama }\end{array}$ & $\begin{array}{l}\text { Tampil pesan "NIP } \\
\text { sudah ada" }\end{array}$ & Sukses \\
\hline & Benar & $\begin{array}{l}\text { Semua textbox diisi } \\
\text { dengan nilai yang } \\
\text { benar }\end{array}$ & $\begin{array}{l}\text { Masuk ke halaman } \\
\text { awal, yaitu halaman } \\
\text { beranda }\end{array}$ & Sukses \\
\hline $\begin{array}{l}\text { Pengujian ubah } \\
\text { pengguna }\end{array}$ & Benar & $\begin{array}{l}\text { Mengubah data } \\
\text { pegawai dengan nilai } \\
\text { yang benar }\end{array}$ & $\begin{array}{l}\text { Tampil pesan sukses } \\
\text { "data berhasil diubah" }\end{array}$ & Sukses \\
\hline
\end{tabular}

\subsection{Menggunakan Prototipe}

Aplikasi yang dibangun setelah melalui tahap pengujian adalah penggunaan aplikasi. Aplikasi Document Flow merupakan sistem yang digunakan untuk mengolah dokumen terkait dengan data disposisi dan pengarsipan dokumen. Sistem ini bertujuan memberikan fasilitas pengelolaan dokumen bagi Divisi PPA-SP dan PPA-MI guna memudahkan dalam mengetahui keberadaan dokumen yang harus didisposisi dan dokumen yang diarsipkan.

\section{KESIMPULAN}

Aplikasi Document Flow modul administrator dan pegawai yang dibangun memiliki kemampuan untuk pengelolaan dan pencarian data yang berhubungan dengan data dokumen, data disposisi, data pegawai pada Divisi PPA-SP, dan mencetak laporan informasi dokumen, informasi disposisi, informasi pegawai dan informasi pencarian dokumen berbentuk PDF dan Excel. Kekurangan dari sistem ini adalah ruang lingkup penggunaannya yang masih terbatas yaitu untuk divisi PPA-SP saja.

Pengembangan dari Aplikasi Document Flow ini dengan memperluas luang lingkup dari aplikasi ini agar bisa digunakan untuk antar divisi tidak hanya 1 divisi dan pada saat pendisposisian dokumen diharapkan penerima dokumennya bisa lebih dari satu orang.

\section{DAFTAR PUSTAKA}

Cyran M. 2005. Oracle Database Concepts, $10 \mathrm{~g}$ Release 2 (10.2).

Kadir A. 2004. Dasar Pemograman Web Dinamis dengan JSP (Java Serve Pages).Yogyakarta : Andi Yogyakarta.

McLeod R dan George P. S. 2008. Sistem Informasi Manajemen. Ed ke-10. Yulianto Ali Akbar dan Fitriani Afia R, penerjemah. Jakarta: Salemba Empat. Terjemahan dari: Management Information System, 10th. Pearson Prentice Hall, Inc.

Navathe SB, Elmasri R. 2011. Fundamentals of Database System $\left(6^{\text {th }}\right.$ ed). United States of America (USA) : Addison-Wesley.

Pressman RS. 2002. Rekayasa Perangkat Lunak, Buku Satu. LN Harnaningrum, penerjemah. Yogyakarta: Andi Yogyakarta. Terjemahan dari: Software Engineering: A Practitioner's Approach.

Satzinger JW, Jackson RB, Burd SD. 2010. System Analysis and Design In a Changing World Fifth Edition. Rosenberg AV, McCormick C, editor. Boston (USA): Course Technology.

Yasin V. 2012. Rekayasa Perangkat Lunak Berorientasi Objek Pemodelan, Arsitektur dan Perancangan (Modelling, Architecture and Design). Jakarta (ID) : MWM. 